\title{
Investigation of Cloud Computing Based Big Data on Machine Learning Algorithms
}

\author{
Muhammed YILDIRIM*, Ahmet ÇINAR, Emine CENGİL \\ Firat University, Department of Computer Engineering, 23100, Elazig, Turkey \\ (ORCID: 0000-0003-1866-4721) (ORCID: 0000-0001-5528-2226) (ORCID: 0000-0003-4313-8694)
}

\begin{abstract}
Cloud computing technology is a model that allows access to a common pool of configurable computing resources whenever and wherever. With the developing technology, the use of this model is increasing day by day. There are many benefits of cloud computing to its users. The data that users keep in their data sets is the simplest example of this. With the cloud technology, the size of the data stored in databases is also increasing. For this reason, cloud technology and big data concepts are intertwined due to the large amount of data stored in databases. It is of great importance that the obtained data is evaluated by machine learning methods and produces results that can be used for technical and commercial purposes. In this study, first of all, cloud technology, the big data brought by this technology and the classification of these data with machine learning methods and algorithms have been examined. Then the studies in the literature were evaluated.
\end{abstract}

Keywords: Big Data, Cloud Computing, Resource Allocation, Machine Learning.

\section{Bulut Bilişim Tabanlı Büyük Verilerin Makine Öğrenmesi Algoritmaları ile İncelenmesi}

\begin{abstract}
Öz
Bulut bilişim teknolojisi, yapılandırılabilir bilişim kaynaklarından oluşan ortak bir havuza, istenildiği zaman ve her yerden erişme imkânı veren bir modeldir. Gelişen teknolojiyle birlikte bu modelin kullanımı gün geçtikçe artmaktadır. Bulut bilişimin kullanıcılarına sunduğu birçok fayda mevcuttur. Kullanıcıların veri setlerinde tuttuğu veriler bunun en basit örneğidir. Bulut teknolojisiyle birlikte veri tabanlarında tutulan verilerin boyutu da artmaktadır. Bu sebeple veri tabanlarında tutulan yüksek miktardaki veriler yüzünden bulut teknolojisi ile büyük veri kavramları iç içe girmiş durumdadır. Elde edilen verilerin makina öğrenmesi yöntemleriyle değerlendirilmesi teknik ve ticari amaçlarla kullanılabilecek şekilde sonuçlar üretmesi büyük bir önem arz etmektedir. Bu çalışmada öncelikle bulut teknolojisi, bu teknolojinin getirmiş olduğu büyük veriler ve bu verilerin makine öğrenmesi yöntemleri ve algoritmaları ile sınıflandırılması incelenmiştir. Daha sonra literatürde yapılan çalışmalar değerlendirilmiştir.
\end{abstract}

Anahtar kelimeler: Büyük Veri, Bulut Bilişsim, Kaynak Tahsisi, Makine Öğrenmesi.

\section{Introduction}

In this study, cloud computing and the accompanying big data, and the interpretation of these data with machine learning methods were examined. Cloud computing technologies enable users to access vast amounts of data [1]. In addition, it enables the storage of large amounts of data in data sets. However, this information kept in data sets does not make sense after it is processed and the necessary inferences are not made. With the developing technology, it is of great importance that these data kept in data sets are processed and benefit institutions, companies or users. Machine learning methods can be used to process these large data sets that come with cloud technology [2]. There are more than one machine learning method in the literature [3]. Processing big data already lies in the logic of the machine learning

*Corresponding author: yldrm23@hotmail.com

Received: 15.03.2021, Accepted: 16.05.2021 
method [4]. Steps such as keeping the customer more on the site by processing the data stored on an ecommerce site, recommending products to the customer, encouraging the customer to shop more can be given to the processing of the data. This process allows the e-commerce site to gain more[5]. This data that can be processed will now become a meaningful data for the e-commerce site. Otherwise, these data will not make sense.

In this study, cloud computing and its sub-titles, machine learning methods used in cloud computing, and later studies conducted with machine learning methods in cloud technology in the literature are presented. In the last part, the title of results and the studies planned to be done in the future are mentioned.

\section{Cloud Computing}

Cloud computing is a widely used service-based technology that enables users to access data at a lower cost and faster, maintains this data, uses the internet and central servers to process and use it [6]. More than one definition is used in cloud computing [7]. Cloud computing can be defined briefly as a technology that allows access to a common pool of configurable computing resources, at any time and from anywhere [8]. Cloud computing is a technology that includes many services, platforms and infrastructures. The cloud computing platform must contain some features. The first of these is that cloud technology should be able to determine the resources according to the need. In other words, the user should be able to update the server processing time and storage space at any time. The cloud computing platform should allow wide network access according to the needs [9]. The user should be able to easily access from devices such as computers and phones. It is another desired feature of the cloud computing platform to be scalable. In addition, the cloud computing platform's resource pooling and providing instant flexibility are very important criteria [10]. Cloud computing and its subtitles are roughly shown in Figure 1.

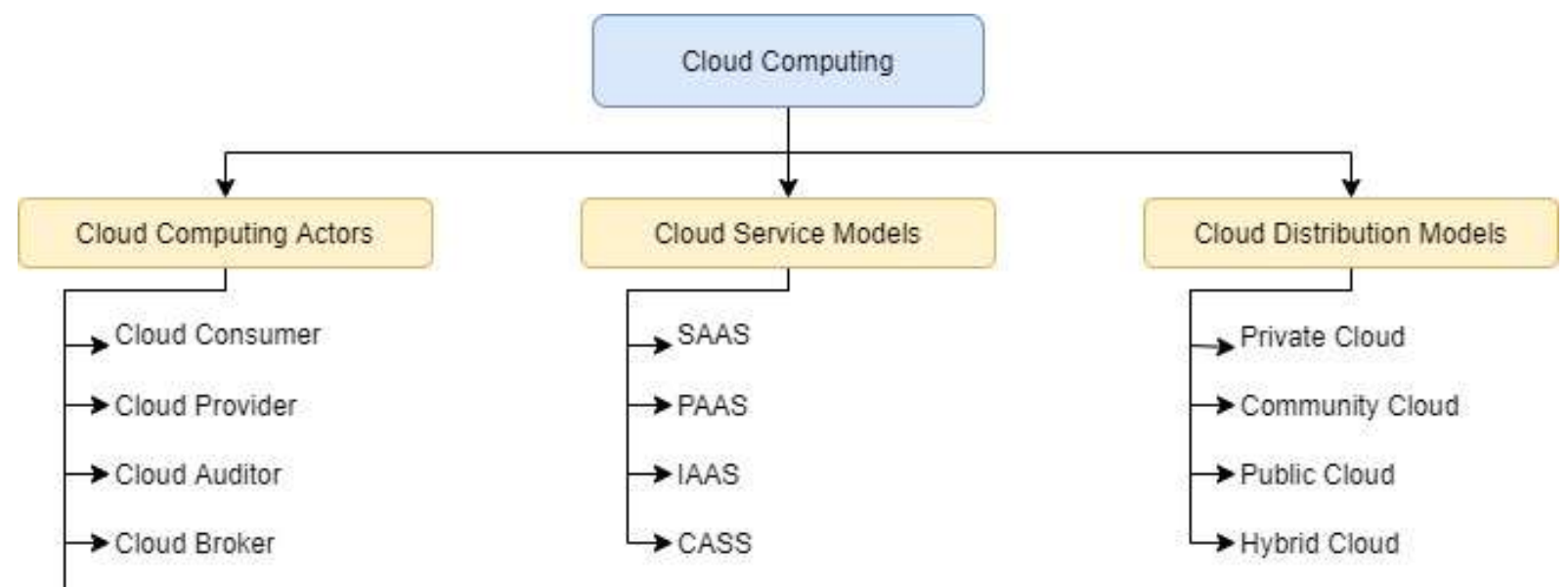

Figure 1. Cloud computing and main components

\subsection{Cloud Computing Actors}

In general, 5 main actors are focused on in cloud computing. These are Cloud Consumer, Cloud Provider, Cloud Auditor, Cloud Broker and Cloud Carrier [11].

\subsubsection{Cloud Consumer}

The cloud consumer is the stakeholder supported by the cloud computing service. Cloud consumer represents an individual or business using the cloud service. Cloud consumer can be roughly defined as the beneficiary of the cloud service. The cloud consumer can get his / her preferred service from the services offered by the cloud provider and these services are subject to the contract they have made with the service provider [12]. 


\subsubsection{Cloud Provider}

The cloud provider is obliged to maintain the continuity of the services, especially the security and confidentiality of these services, by managing the required software, platform and infrastructure services. The cloud provider can be in an entity used by an individual, organization, or consumers [13].

\subsubsection{Cloud Auditor}

Cloud auditor are controllers that can connect to cloud services and control these service providers by considering criteria such as security, privacy and performance. These auditors can be third party persons or organizations [14].

\subsubsection{Cloud Broker}

Due to the developing technology, users cannot directly contact the cloud computing service provider. Instead, it communicates with a cloud agent. The cloud agent is an entity that regulates the relationship of cloud services between the user and the cloud provider, increasing performance and availability [15].

\subsubsection{Cloud Carrier}

Cloud carrier performs connections and transfers between cloud providers of cloud services and cloud users. It provides software installation in the cloud infrastructure, software management, maintenance and support of these software [16].

\subsection{Cloud Service Models}

\subsubsection{SAAS}

It refers to the users' ability to connect and use internet-based applications remotely. These applications are based on pay-as-you-go logic. Applications such as social networks, office programs, e-mail, calendars can be given as examples [17].

\subsubsection{PAAS}

It is a cloud environment that allows to deploy everything from simple-based applications to advanced applications in cloud computing. Programming languages, frameworks, structural data can be given as examples. This platform is based on pay-as-you-go logic [18].

\subsubsection{IAAS}

It is known as the virtual infrastructure manager. It is an instant information processing infrastructure that is provided and managed over the Internet. It is roughly known as the virtual infrastructure manager. Examples include compute server, firewall, load balancer, and data storage[19].

\subsubsection{CAAS}

The cloud server hosts an image taken from the user and allows the user to use it from anywhere. This brings a scalable advantage to the user [20]. An example of this is Google Cloud Run.

\subsection{Cloud Distribution Model}

Private cloud, community cloud, public cloud, hybrid cloud are the most well-known computing distribution models [21]. 


\subsubsection{Private Cloud}

An organization, institution, company or user has its own cloud infrastructure built on its own data centers and offers its own services. In this way, users can manage their own security and privacy policies. This model is not available to everyone. It belongs to the institution, organization or user. It only serves its own users [22].

\subsubsection{Community Cloud}

It is the process of sharing cloud services by more than one institution or organization. These communities open their data canter's to common use and use existing services together. Thus, resources are shared with less cost. Community clouds are often related to each other [23].

\subsubsection{Public Cloud}

This cloud, which is accepted as a standard, offers application and infrastructure services to users by a third party cloud provider. It is possible for more than one user to access the services offered here. Since all services such as hardware and infrastructure are provided by the service provider, it is easier and less expensive to install than other cloud models. This cloud model is charged by the amount used by the user [24].

\subsubsection{Hybrid Cloud}

They are structures where at least 2 cloud models are used together. This cloud model is intended to work together with cloud-based systems brought together. With this cloud model, a more flexible working platform is provided. The main goal here is to provide a better cloud service [25].

\section{Cloud Computing and Machine Learning}

It has become an important issue to examine the data in the big data sets coming with cloud computing with machine learning methods [26]. It is of great importance to process these data in public and commercial areas. These data are of great importance in the public and private sector. Considering this for an e-commerce site, it is a big problem that a customer makes inferences from which product he is looking at, recommends other products to the customer accordingly, and also keeps the customer on the site. Big data, cloud computing systems and machine learning methods will increase both production efficiency and sales capacity and provide a great decrease in costs [27]. Due to all these features, machine learning methods can be used to process this data. Machine learning is roughly as given in Figure 2.

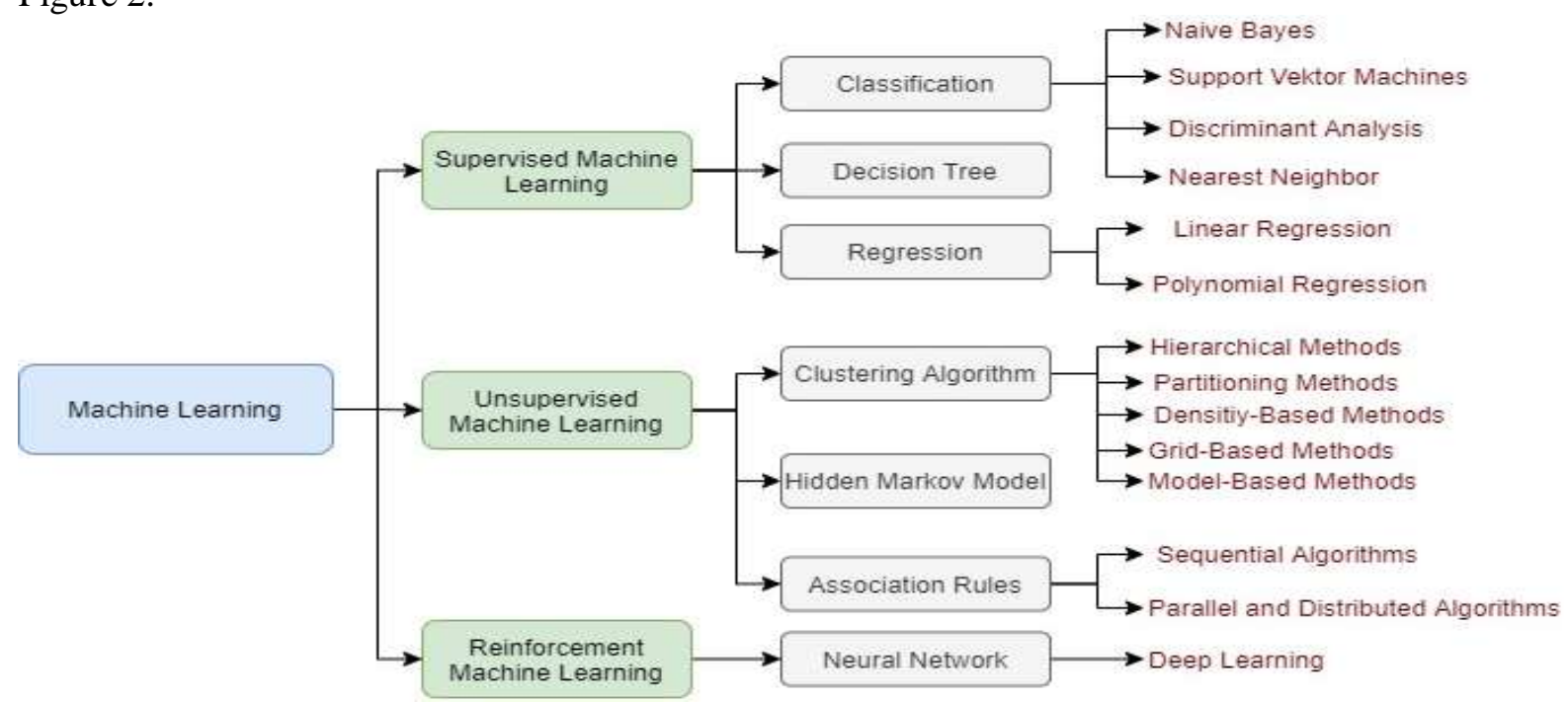

Figure 2. Machine learning approaches 


\subsection{Supervised Machine Learning}

The basic logic of supervised machine learning is the learning of the network by giving sample data to the network. The trained network is required to produce the closest result to the desired value for the new inputs that will come later [28]. This process is roughly given in equation 1.

$Y=f(X)$

$X$ : input values, $Y$ : output values

It is possible to categorize supervised machine learning in 3 classes.

\subsubsection{Classification}

It is the process of separating these data into categories by making a conclusion from the data observed with the machine learning algorithm and determining which category belongs to the new data that will come later. This method can be used if it is desired to categorize the roughly used data. The number of classes is not important here, the important thing is that the data is labelled [29]. The label refers to the class of the data. With the developing technology, there are more than one classification method currently used [30]. The most known methods are given in figure 2 .

Naive Bayes: The naive bayes classification, which is a statistical classification method, is based on the bayes theorem in statistics. The probability of whether the available data belongs to the specified classes is evaluated. It contains the logic of probabilistic calculation of the effect of each criterion of the data on the result. Naive Bayes method is frequently used in cloud technologies due to its simplicity and simplicity compared to other classification algorithms [31]. Naive bayes data classification is roughly given in Figure 3.

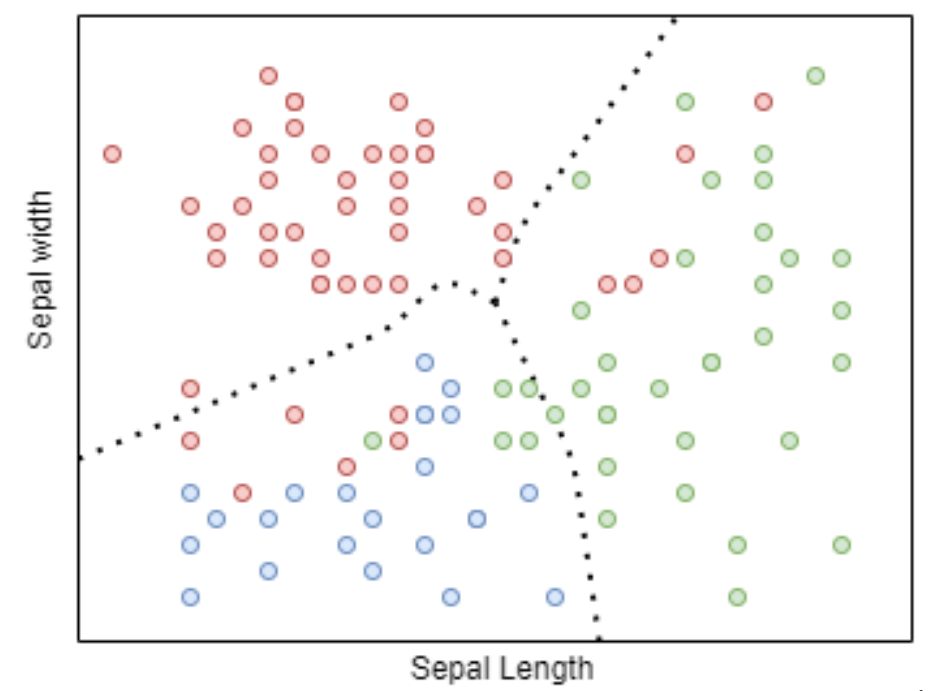

Figure 3. Naive bayes data classification

Support Vector Machines: Support Vector Machines is a technique used to logically separate data belonging to more than one class from each other in the most appropriate way. For this, decision boundaries or in other words, hyper planes are determined. Support vector machines can produce successful results in high dimensional spaces. In addition, memory is used efficiently thanks to the training points they have used. The data set used can be of 2 types. The first of these are data sets that can be decomposed linearly and the other is nonlinearly decomposable [32]. Data sets that can be linearly separated and not linearly separated by using support vector machines are roughly shown in Figure 4. 

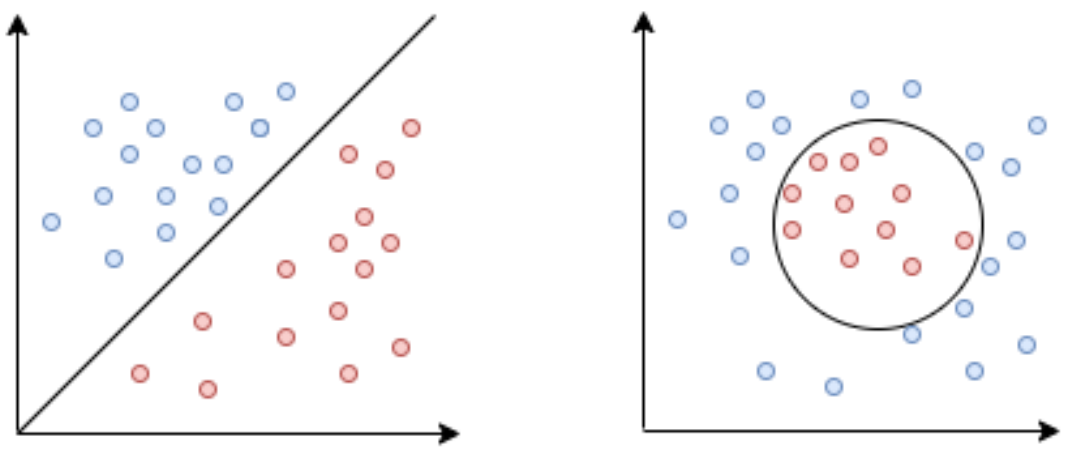

Figure 4. SVM classification notation

Discriminant Analysis: Discriminant analysis method is a preferred method to make the data easier to separate in cases where more data sets are complex. It uses the covariance matrix to perform this process. DA examines the distribution of classes to distinguish between classes in the data set and uses the difference between the average values of these classes. It examines the distribution of classes and uses the difference between their mean values to distinguish between classes [33]. PCA and LDA are the most widely used methods.

K- Nearest Neighbors (KNN): The KNN algorithm is an algorithm that works by looking at the proximity of the data to be classified to $\mathrm{k}$ of the previous data. In the classification phase, test and training data are compared with each other. In these comparisons, Euclidean connection is more preferred in measuring neighborhood distances. This method can be preferred to extract information from the large data sets that come with cloud technology [34]. This algorithm is a type of algorithm that can be successful against noisy data.

\subsubsection{Decision Tree}

Decision trees are one of the most preferred methods in classification. Decision trees have a predefined variable. Due to their structure, they have a structure that expands from the top to the bottom. Decision trees are a method used to divide data sets that have a large number of data into smaller clusters. It is a hierarchical data structure that represents data with a divide and conquer strategy. Being easy to understand and interpret, and processing both numerical and categorical data are the reasons why this method is frequently preferred. Decision trees consist of knots and leaves [35]. The structure of the decision tree is shown in Figure 5. In the figure, every internal node tests a feature. Leaf node corresponds to the attribute value. Each leaf node assigns a classification.

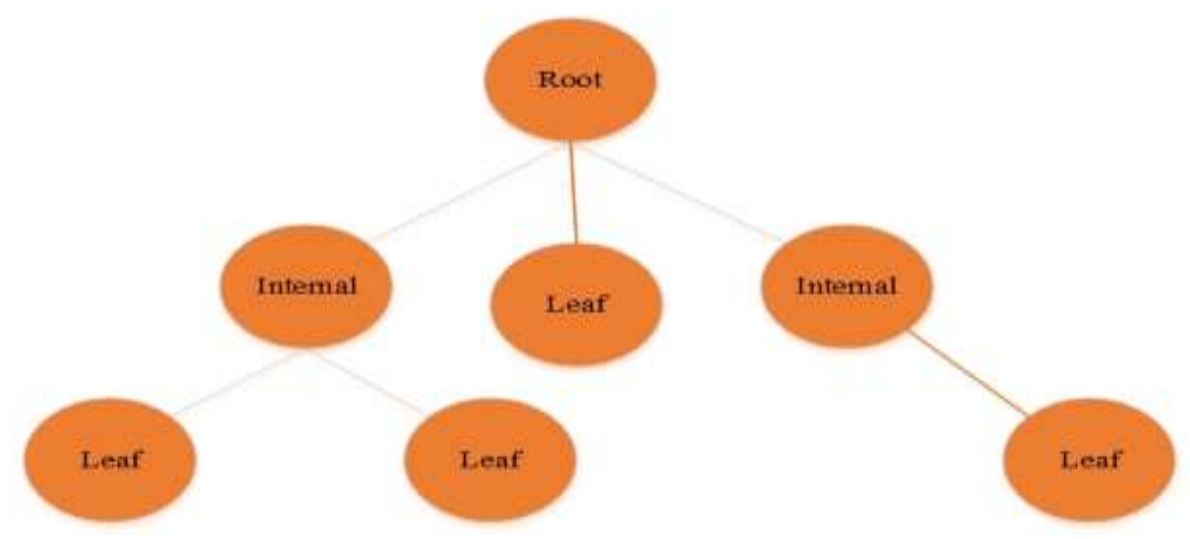

Figure 5. Decision Tree

\subsubsection{Regression}

Regression analysis is one of the main areas of statistical science. The process of predicting the behaviour of a random variable using a model. Here, the relationships of dependent and independent variables with each other are examined. Thanks to this relationship between variables, the modelling or 
estimation process is performed. There are more than one type of regression used in statistics [36]. In this study, the most frequently used methods in the classification of big data sets that come up with cloud technology are mentioned.

Linear Regression: If there is a linear relationship between the predicted data and the variables in the study, linear regression is preferred [37]. Linear Regression curve and the representation of the data are given in Figure 6.

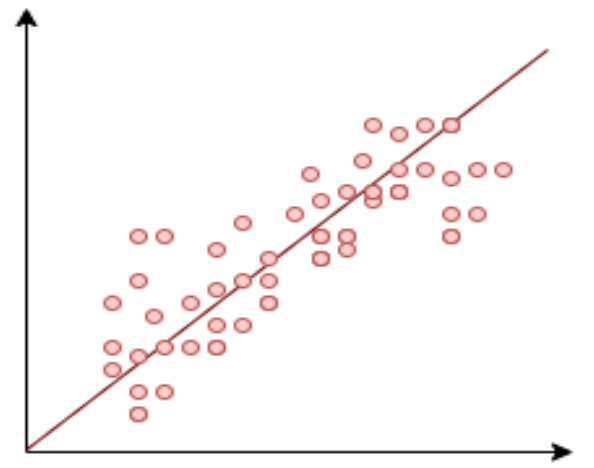

Figure 6. Linear Regression

Polynomial Regression: If the distribution of available data is not linearly distributed, then it will not be possible to draw a linear regression curve. In this case, polynomial regression can be used to divide the data set. The regression curve to be drawn is polynomial and is given in Figure 7.

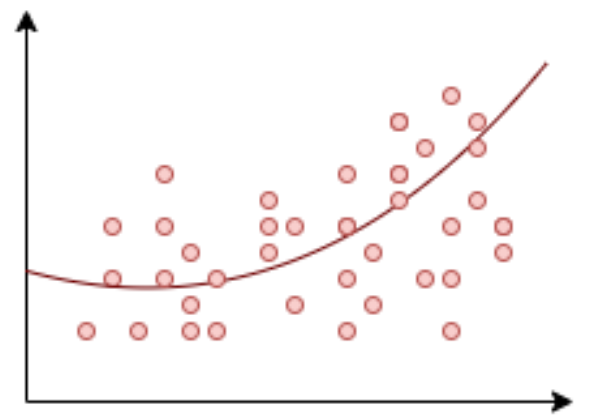

Figure 7. Polynomial Regression

\subsection{Unsupervised Machine Learning}

Unsupervised learning models are in the descriptive model category. Because here the models are not meant to predict a particular outcome. In these methods, the relationships between the data in the data sets are revealed. Through the detected relationships, the data are divided into groups according to their proximity. In this way, the new data that comes as input is taken into the relevant group according to the proximity [38].

\subsubsection{Clustering Algorithms}

It is aimed to obtain a homogeneous sub-data group from a heterogeneous data group by dividing the data into clusters consisting of similar elements. Most of the clustering methods use distances between data. The most common of these are Euclidean distance, Manhattan distance, and Minkowski distance. The main methods used in clustering methods are given respectively [39].

Hierarchical Methods: Hierarchical methods are based on grouping objects in the form of a tree structure called dendogram. These methods do not need to know the number of clusters. These methods are the methods that enable the gradual combination of sets considered separately. There is more than one hierarchical method in the literature. The best known of these are the closest neighbor algorithm and the furthest neighbor algorithm.

Partitioning Methods: Partition methods are the process of dividing a database of $n$ objects into $\mathrm{k}$ sections specified as input parameters. Each data in the database is placed in one of the $\mathrm{k}$ sections 
according to the difference function. Each section obtained here is called a cluster. K-means algorithm and k-medoids algorithm are among the most known algorithms.

Density Based Methods: A threshold value is determined in density-based methods. Then, according to this threshold value, the distribution of objects is computed with a density function and decomposed into clusters. These are the methods with high success in finding clusters. It can be used comfortably in cloud computing as it is not affected by noise and exceptions much.

Grid Based Methods: This method uses grid structures consisting of a finite number of square cells to examine the data space. Cloud computing is among the methods that can be preferred, as they can work independently of the number of objects in the database due to the grid format they use.

Model Based Methods: In this method, the data are expressed with an algebraic model. Modelbased methods are among the preferred models in cloud computing because they use the statistical approach and artificial intelligence approach.

\subsubsection{Hidden Markov Model}

In this model, situations cannot be observed from the outside, only the observation outputs of each situation can be viewed. In this model, all observations are independent of the model. The Markov process provides probabilistic information about the future state of an event happening now. The usage area of this model is quite wide. This model is widely used in many areas such as marketing, education, and finance [40]. Therefore, this model is among the models that can be used in cloud computing.

\subsubsection{Association Rules}

Association rules are a method that resolves the situations of co-occurrence of events. Association rules are also used to define simultaneous partnerships. It can find the relationships between data different from the big data sets emerging with cloud computing and perform the interpretation process. It is used extensively, especially in the marketing sector. In addition, it is used in many fields such as economy, telecommunication, e-commerce, health and marketing due to its usefulness and easy understanding [41]. It is possible to categorize the algorithms used in association rules extraction under two headings as sequential and parallel.

Sequential Algorithms: While creating association rules, it is accepted that many data are defined sequentially and kept in databases in this way. It is an approach that provides convenience when creating object sets of ordered objects in sorting algorithms. Ais, Apriori, Setm, Partitioning algorithm, Sampling algorithm, Carma and Fp-Growth are the most well-known sequential algorithms [42]. This group constitutes the most preferred algorithms group in cloud computing.

Parallel and Distributed Algorithms: Parallel algorithms focus on paralleling the process of finding object clusters. Parallel and distributed algorithms generally work on paralleling logic. In the working logic of these algorithms, either the data is parallelized or the task is parallelized. While processing large amounts of data sets that come with cloud computing, the parallel features of these models can be used. Count Distribution, Parallel Data Mining, Distributed Mining Algorithm, Common Candidate Partitioned Database, Data Distribution, Intelligent Data Distribution, Skew Handling and Hybrid Distribution are the most well-known algorithms [43]. Since these algorithms can work in parallel, they have taken their place among the preferred algorithms in cloud technology.

\subsection{Reinforcement Machine Learning}

Reinforcement learning is an approach that learns from past experience what choices need to be made to reach the highest value. The difference of this algorithm from classical methods is that it does not need prior knowledge.

\subsubsection{Artificial neural networks}

Artificial neural networks are designed with inspiration from the human brain. The learning process is carried out with mathematical models. Artificial neural networks consist of many cells and these cells can perform complex tasks. These networks can be trained with different learning algorithms. They can 
be used in many areas such as pattern recognition and classification. Since they have a wide range of uses, they have taken their place among the most preferred methods in cloud computing [44].

Deep Learning: Deep learning is one of the most popular machine learning methods in recent years. Deep learning architectures consist of multiple layers. The exit of each layer becomes the entrance of the next layer. In deep learning models, feature maps are extracted and models are trained. The trained models are then tested with test data and the performance performances of the models are evaluated. Outputs are estimated according to the given input data. After the models are trained, new data are placed in the relevant class. Deep learning is widely used in many areas such as face recognition, speech recognition, image processing, cyber-attack analysis, and alarm systems. Deep learning is among the most used methods in cloud computing [45].

\section{Literature Review}

Zhang et al. Investigated intelligent cloud resource management with deep intelligent empowerment methods in their study in 2017. They stated that cloud computing provides low-cost and flexible hardware and software resources over the internet. They also stated that there is an increasing trend towards using machine learning to improve the intelligence of cloud management. In their study, they stated that they examined a smart cloud resource management architecture that includes comprehensive empowerment learning. They stated that one of the best algorithms in this type of learning is DQN learning and the main idea of this is to create a Q table. They also talked about the Markov decision process in their work [46].

Barnes did a detailed study on Azure machine learning in 2015. He explained in detail what machine learning is, the relationship of machine learning with cloud computing, training networks, testing models, client and server applications. He also detailed the relationship of cloud computing with regression analysis and clustering methods [47].

Botchkarev aimed to evaluate the Performance of Regression Machine Learning Models in cloud-based Azure Machine Learning Studio in his study in 2018. He performed this process by using Multiple Error Measures in his study [48].

Rajagopal et al. Conducted a performance analysis of binary and multi-class models using cloud computing azure machine learning methods in their study in 2020. In addition, they used more than one classifier in their study [49].

Abdelaziz et al. Proposed a machine learning model to improve healthcare services in a cloud computing environment in their study in 2018. Recently, they stated that cloud computing has been widely used in the field of health, but choosing the optimum virtual machine is very difficult. In order to avoid the difficulty of selecting the optimum virtual machine based on incoming medical demands, they proposed a new model based on the cloud environment using Parallel Particle Swarm Optimization. In addition, they stated that the model they proposed was more successful than the other models in the literature [50].

Tuli et al. Stated in their study in 2020 that they aimed to predict the growth and trend of the COVID-19 epidemic using machine learning and cloud computing. They stated that they proposed a new model to predict the impact of the Covid19 outbreak, and that this model was based on real-time, cloud computing and machine learning. In addition, they calculated the metrics values of many countries in their study [51].

Wang et al. Used Machine Learning approaches for Cloud Computing Supported Resource Allocation in their study in 2018. They stated that since most of the resource allocation problems are not convex, it is difficult to get optimal solutions in real time. They stated that the system they proposed was more successful than traditional resource allocation methods [52].

Zhang et al. Used machine learning methods for resource allocation in cloud computing in their study in 2018. They stated that resource allocation in cloud computing is an NP problem and cannot be solved in polynomial time. In their study, they used machine learning methods to model and analyse the multidimensional cloud resource allocation problem. They proposed two resource allocation algorithms based on linear and logistic regression. They stated that the algorithms they proposed got good results [53].

Chiba et al. Stated in their study in 2019 that cyber-attacks have increased with the advancing cloud technology and that attacks from outside may occur. They stated that they recommended a 
machine learning-based intrusion detection system to detect and prevent these anomalies and attacks. They stated that their models are successful in detection rate and they can be used comfortably in cloud computing [54].

Zekri et al. Stated in their study in 2017 that they performed DDoS attack detection using machine learning techniques in cloud computing environments. They used decision trees, one of the machine learning classifiers, to detect DDoS attacks. They compared their results with traditional results [55].

Table 1. Studies on the subject

\begin{tabular}{|c|c|c|l|}
\hline Article & Year & Language & \multicolumn{1}{|c|}{ Subject } \\
\hline$[46]$ & 2017 & English & $\begin{array}{l}\text { Investigated intelligent cloud resource management with deep } \\
\text { intelligent empowerment methods }\end{array}$ \\
\hline$[47]$ & 2015 & English & $\begin{array}{l}\text { Relationship of machine learning with cloud computing, training } \\
\text { networks, testing models, client and server applications }\end{array}$ \\
\hline$[48]$ & 2018 & English & $\begin{array}{l}\text { Performance of Regression Machine Learning Models in cloud- } \\
\text { based }\end{array}$ \\
\hline$[49]$ & 2020 & English & Using cloud computing azure machine learning methods \\
\hline$[50]$ & 2018 & English & $\begin{array}{l}\text { Machine learning model to improve healthcare services in a cloud } \\
\text { computing environment }\end{array}$ \\
\hline$[51]$ & 2020 & English & $\begin{array}{l}\text { Proposed a new model to predict the impact of the Covid19 } \\
\text { outbreak, and that this model was based on real-time, cloud } \\
\text { computing and machine learning }\end{array}$ \\
\hline$[52]$ & 2018 & English & $\begin{array}{l}\text { Used Machine Learning approaches for Cloud Computing } \\
\text { Supported Resource Allocation }\end{array}$ \\
\hline$[53]$ & 2018 & English & $\begin{array}{l}\text { Used machine learning methods for resource allocation in cloud } \\
\text { computing }\end{array}$ \\
\hline$[54]$ & 2019 & English & $\begin{array}{l}\text { Using machine learning in cyber-attacks with the developing } \\
\text { cloud technology }\end{array}$ \\
\hline$[55]$ & 2017 & English & $\begin{array}{l}\text { DDoS attack detection using machine learning techniques in } \\
\text { cloud computing environments }\end{array}$ \\
\hline
\end{tabular}

\section{Conclusion}

Studies involving cloud computing and machine learning have started to be carried out especially in recent years. Developing cloud technology brings along big data sets. In order for these data sets to become meaningful, machine learning methods should be used effectively. Processing these data sets with other methods is a very difficult process. Machine learning has recently become one of the most important issues such as cloud computing. We believe that these studies should produce instant results via cloud computing in order to yield effective results. In particular, instant evaluation of critical data is of great importance.

\section{Author's Contributions}

All authors contributed equally.

\section{Conflict of Interest Statement}

There is no conflict of interest between the authors.

\section{Research and Publication Ethics Statement}

The authors declare that this study complies with Research and Publication Ethics.

\section{References}

[1] Aceto G., Persico V., Pescapé A. 2020. Industry 4.0 and health: Internet of things, big data, and cloud computing for healthcare 4.0. Journal of Industrial Information Integration, 18: 100129. 
[2] Mrozek D., Koczur A., Małysiak-Mrozek B. 2020. Fall detection in older adults with mobile IoT devices and machine learning in the cloud and on the edge. Information Sciences, 537: 132-147.

[3] Yildirim M., Cinar A. 2020. A deep learning based hybrid approach for COVID-19 disease detections. Traitement du Signal, 37 (3): 461-468.

[4] Morariu C., Morariu O., Răileanu S., Borangiu T. 2020. Machine learning for predictive scheduling and resource allocation in large scale manufacturing systems. Computers in Industry, 120: 103244.

[5] Tang S., He B., Yu C., Li Y., Li K. 2020. A survey on spark ecosystem: Big data processing infrastructure, machine learning, and applications. IEEE Transactions on Knowledge and Data Engineering.

[6] Namasudra S., Devi D., Kadry S., Sundarasekar R., Shanthini A. 2020. Towards DNA based data security in the cloud computing environment. Computer Communications, 151: 539-547.

[7] Sunyaev A. 2020. Cloud computing. In Internet computing. Springer, Cham, 195-236.

[8] Soh J., Copeland M., Puca A., Harris M. 2020. Overview of Azure Infrastructure as a Service (IaaS) Services. In Microsoft Azure, Apress, Berkeley, CA., 21-41.

[9] Caiza G., Saeteros M., Oñate W., Garcia M.V. 2020. Fog computing at industrial level, architecture, latency, energy, and security: A review. Heliyon, 6 (4): e03706.

[10] Liu S., Chan F.T., Yang J., Niu B. 2018. Understanding the effect of cloud computing on organizational agility: An empirical examination. International Journal of Information Management, 43: 98-111.

[11] De la Prieta F., Rodríguez-González S., Chamoso P., Corchado J.M., Bajo J. 2019. Survey of agent-based cloud computing applications. Future Generation Computer Systems, 100: 223-236.

[12] Kholidy H.A. 2020. An intelligent swarm based prediction approach for predicting cloud computing user resource needs. Computer Communications, 151: 133-144.

[13] Hassan H., El-Desouky A.I., Ibrahim A., El-Kenawy E.S.M., Arnous R. 2020. Enhanced QoSbased model for trust assessment in cloud computing environment. IEEE Access, 8: 43752-43763.

[14] Taha A.A., Ramo W., Alkhaffaf H.H.K. 2021. Impact of external auditor-cloud specialist engagement on cloud auditing challenges. Journal of Accounting \& Organizational Change. https://doi.org/10.1108/JAOC-08-2020-0111.

[15] Kurdi H., Alsalamah S., Alatawi A., Alfaraj S., Altoaimy L., Ahmed S.H. 2019. HealthyBroker: a trustworthy blockchain-based multi-cloud broker for patient-centered ehealth services. Electronics, 8 (6): 602.

[16] Tamimi A.A., Dawood R., Sadaqa L. 2019. Disaster recovery techniques in cloud computing. In 2019 IEEE Jordan International Joint Conference on Electrical Engineering and Information Technology (JEEIT), IEEE, 845-850.

[17] Hajji M.A., Mezni H. 2018. A composite particle swarm optimization approach for the composite saas placement in cloud environment. Soft Computing, 22 (12): 4025-4045.

[18] Zaitsev D., Luszczek P. 2020. Docker container based PaaS cloud computing comprehensive benchmarks using LAPACK. In CMIS, 323-337.

[19] Sanaj M.S., Prathap P.J. 2020. Nature inspired chaotic squirrel search algorithm (CSSA) for multi objective task scheduling in an IAAS cloud computing atmosphere. Engineering Science and Technology, an International Journal, 23 (4): 891-902.

[20] Pratama I.P.A.E. 2021. The implementation of Container as a Service (CaaS) cloud using openSUSE kubic. Global Journal of Engineering and Technology Advances, 6 (1): 001-009.

[21] Namasudra S. 2021. Data access control in the cloud computing environment for bioinformatics. International Journal of Applied Research in Bioinformatics (IJARB), 11 (1): 40-50.

[22] Tavbulatova Z.K., Zhigalov K., Kuznetsova S.Y., Patrusova A.M. 2020. Types of cloud deployment. In Journal of Physics: Conference Series, IOP Publishing, 1582 (1): 012085).

[23] Qureshi A., Sharma A. 2021. Cloud Computing: The New World of Technology. In Proceedings of Second International Conference on Smart Energy and Communication, Springer, Singapore, $55-60$.

[24] Xu Y., Sun S., Cui J., Zhong H. 2020. Intrusion-resilient public cloud auditing scheme with authenticator update. Information Sciences, 512: 616-628.

[25] Talaat M., Alsayyari A.S., Alblawi A., Hatata A.Y. 2020. Hybrid-cloud-based data processing for power system monitoring in smart grids. Sustainable Cities and Society, 55: 102049. 
[26] Stergiou C.L., Plageras A.P., Psannis K.E., Gupta B.B. 2020. Secure machine learning scenario from big data in cloud computing via internet of things network. In Handbook of computer networks and cyber security, Springer, Cham, 525-554.

[27] Ionescu L., Andronie M. 2021. Big Data Management and Cloud Computing: Financial Implications in the Digital World. In SHS Web of Conferences, Vol: 92, EDP Sciences.

[28] Cengil E., Çinar A. 2020. Göğüs Verileri Metrikleri Üzerinden Kanser Sınıflandırılması. Dicle Üniversitesi Mühendislik Fakültesi Mühendislik Dergisi, 11 (2): 513-519.

[29] Yildirim M., Cinar A. 2020. Classification of Alzheimer's Disease MRI Images with CNN Based Hybrid Method. Ingénierie des Systèmes d'Information, 25 (4).

[30] Uçkan T., Hark C., Karci A. 2021. SSC: Clustering of Turkish texts by spectral graph partitioning. Politeknik Dergisi, https://doi.org/10.2339/politeknik.684558.

[31] Kim H.C., Park J.H., Kim D.W., Lee J. 2020. Multilabel naïve Bayes classification considering label dependence. Pattern Recognition Letters, 136: 279-285.

[32] Li L.L., Zhao X., Tseng M.L., Tan R.R. 2020. Short-term wind power forecasting based on support vector machine with improved dragonfly algorithm. Journal of Cleaner Production, 242: 118447.

[33] Özdemir A., Şahan M.H. 2020. Radiologic features of symptomatic cholelithiasis: a current perspective. Journal of Health Sciences and Medicine, 3 (4): 466-472.

[34] Yaşar Ş., Çolak C. 2020. A Proposed Model Can Classify the Covid-19 Pandemic Based on the Laboratory Test Results. The Journal of Cognitive Systems, 5 (2): 60-63.

[35] Kaçmaz A., Yildiz K., Buldu A. 2020. An Application on Technology Addiction with C4. 5 Classification Algorithm. Bitlis Eren Üniversitesi Fen Bilimleri Dergisi, 9 (4): 1756-1765.

[36] Naji D.M., Akin M.K., Cabalar A.F. 2021. Evaluation of seismic site classification for Kahramanmaras City, Turkey. Environmental Earth Sciences, 80 (3): 1-17.

[37] Jiao S., Gao Y., Feng J., Lei T., Yuan X. 2020. Does deep learning always outperform simple linear regression in optical imaging?. Optics express, 28 (3): 3717-3731.

[38] Yildirim M., Çinar A. 2019. Simultaneously Realization of Image Enhancement Techniques on Real-Time Fpga. In 2019 International Artificial Intelligence and Data Processing Symposium (IDAP), IEEE, 1-6.

[39] Yildirim M., Çinar A. 2019. Use of Fpga for Real-Time K-Means Clustering Algorithm. International Journal of Engineering Science and Application, 3 (3): 130-136.

[40] Wang X., Xu W., Jin Z. 2017. A hidden Markov model based dynamic scheduling approach for mobile cloud telemonitoring. In 2017 IEEE EMBS International Conference on Biomedical \& Health Informatics (BHI), IEEE, 273-276.

[41] Osadchiy T., Poliakov I., Olivier P., Rowland M., Foster E. 2019. Recommender system based on pairwise association rules. Expert Systems with Applications, 115: 535-542.

[42] Powell T. 2018. Sequential algorithms and the computational content of classical proofs. arXiv preprint arXiv: 1812.11003.

[43] Levchenko O., Kolev B., Yagoubi D.E., Shasha D., Palpanas T., Valduriez P., Masseglia, F. 2019. Distributed algorithms to find similar time series. In Joint European Conference on Machine Learning and Knowledge Discovery in Databases, Springer, Cham, 781-785.

[44] Çinar A., Yildirim M. 2020. Detection of tumors on brain MRI images using the hybrid convolutional neural network architecture. Medical hypotheses, 139: 109684.

[45] Yildirim M., Çinar A. 2019. Classification of White Blood Cells by Deep Learning Methods for Diagnosing Disease. Revue d'Intelligence Artificielle, 33 (5): 335-340.

[46] Zhang Y., Yao J., Guan H. 2017. Intelligent cloud resource management with deep reinforcement learning. IEEE Cloud Computing, 4 (6): 60-69.

[47] Barnes J. 2015. Azure machine learning. Microsoft Azure Essentials. 1st ed, Microsoft.

[48] Botchkarev A. 2018. Evaluating performance of regression machine learning models using multiple error metrics in Azure Machine Learning Studio Available at SSRN 3177507.

[49] Rajagopal S., Hareesha K.S., Kundapur P.P. 2020. Performance analysis of binary and multiclass models using azure machine learning. International Journal of Electrical \& Computer Engineering, 10 (1): 2088-8708.

[50] Abdelaziz A., Elhoseny M., Salama A.S., Riad A.M. 2018. A machine learning model for improving healthcare services on cloud computing environment. Measurement, 119: 117-128. 
[51] Tuli S., Tuli S., Tuli R., Gill S.S. 2020. Predicting the growth and trend of COVID-19 pandemic using machine learning and cloud computing. Internet of Things, 11: 100222.

[52] Wang J.B., Wang J., Wu Y., Wang J.Y., Zhu H., Lin M., Wang J. 2018. A machine learning framework for resource allocation assisted by cloud computing. IEEE Network, 32 (2): 144-151.

[53] Zhang J., Xie N., Zhang X., Yue K., Li W., Kumar D. 2018. Machine learning based resource allocation of cloud computing in auction. Comput. Mater. Continua, 56 (1): 123-135.

[54] Chiba Z., Abghour N., Moussaid K., Rida M. 2019. Intelligent approach to build a Deep Neural Network based IDS for cloud environment using combination of machine learning algorithms. Computers \& Security, 86: 291-317.

[55] Zekri M., El Kafhali S., Aboutabit N., Saadi Y. 2017. DDoS attack detection using machine learning techniques in cloud computing environments. In 2017 3rd International Conference of Cloud Computing Technologies and Applications (CloudTech) IEEE, 1-7. 